ఠ

\title{
Surgical treatment of elephantiasis of the feet in congenital lymphedema to facilitate the use of a compression mechanism
}

This article was published in the following Dove Press journal:

International Journal of General Medicine

4 March 2010

Number of times this article has been viewed

\author{
José Maria Pereira de \\ Godoy' \\ Lina MO Azoubel ${ }^{2}$ \\ Maria de Fátima Guerreiro \\ Godoy ${ }^{2,3}$ \\ 'Department of Cardiology and \\ Cardiovascular Surgery, Medicine \\ School of São Jose do Rio Preto- \\ FAMERP, Brazil; ' Godoy Clinic, \\ Lymphovenous Rehabilitation, \\ Medicine School, São José do Rio \\ Preto-FAMERP, Brazil; ${ }^{3}$ CAPES \\ (Coordination of improvement of \\ Personal of Superior Level), Rio de \\ Janeiro, Brazil
}

\begin{abstract}
The aim of the current study is to report on the minimal surgical treatment of elephantiasis of the feet to facilitate the use of compression mechanisms. The cases of two patients with congenital lymphedema that evolved to elephantiasis involving the feet are reported. Intensive treatment of the lymphedema was performed with a significant reduction in size thus allowing a better identification of the limits of tissue masses for the surgical approach. This reduction enabled primary suturing of the lesions to be carried out and fast healing of the wounds. The surgery greatly improved large deformities of the toes and feet and facilitated further treatment of the lymphedema using bandaging. Thus, the skin was preserved, there was a reduction in the size of the feet, and the patients were able to start wearing shoes.
\end{abstract}

Keywords: elephantiasis, surgical treatment, feet, lymphedema

\section{Introduction}

Lymphedema is a type of edema that occurs due to an abnormal accumulation of fluids and other substances in the tissues resulting from failure of the lymphatic system associated with insufficiency of extralymphatic proteolysis of proteins in the cell interstice and the mobilization of macromolecules, ${ }^{1}$ including hyaluronic acid. ${ }^{2}$ The progression of lymphedema to elephantiasis associated to an increased incidence of episodic adenolymphangitis is of great concern, as it causes physical suffering, permanent disability and economic loss to patients. ${ }^{3}$

Lymph drainage, ${ }^{4}$ exercising, ${ }^{5}$ hygiene care,${ }^{6}$ compression mechanisms, ${ }^{7}$ and more recently the association of occupational activities, ${ }^{8}$ and cervical stimulation ${ }^{9}$ are recommended in the treatment of lymphedema. Excisional surgical therapy can be effective for chronic advanced lymphedema, but appropriate postoperative physiotherapy is essential to ensure that the results last. ${ }^{10}$

The aim of the current study is to report on the surgical treatment of elephantiasis of the feet in order to facilitate the use of compression mechanisms.

\section{Case report I}

The case of a 64-year-old patient, who suffers from congenital lymphedema of the legs which evolved to elephantiasis despite different types of therapy, is reported (Figures 1 and 2). Intensive treatment of the lymphedema was performed using manual lymph drainage (about one hour per day) simultaneously associated with mechanical lymph drainage using the RAGodoy apparatus ${ }^{10}$ (for seven to eight hours daily) and homemade compression stockings made from a cotton-polyester material around the thigh
Correspondence: José Maria Pereira de Godoy

Rua Floriano Peixoto, 2950, São José do Rio Preto, SP - Brazil CEP: I50200I0

Email godoyjmp@riopreto.com.br 

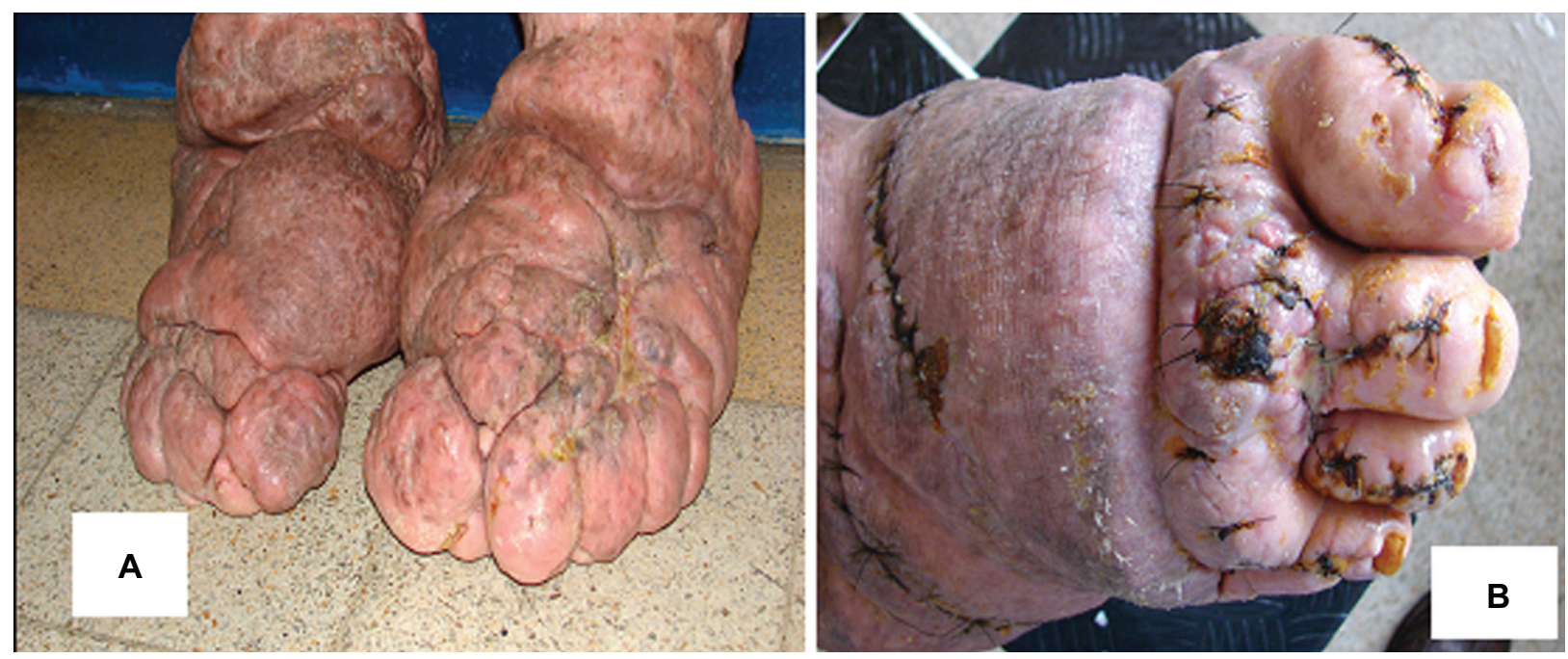

Figure I Before and after reconstruction surgery of the foot and toes.

and leg. This stocking was developed, after studies by the authors, using a material which in Brazil is called gorgurão. ${ }^{11}$ This material is a mixture of $50 \%$ cotton and $50 \%$ polyester and thus has the characteristics of being low stretch and inexpensive; this is important as most of the patients have low incomes. For personal hygiene, the stockings can be put on and removed by the patient and thus provide independence. The stockings are made similar to commercial madeto-measure stockings with Velcro or hook-and-eye fasteners being used so that the patient can adjust the size and thus the pressure exerted by the garment. A reduction in the size of the thighs and feet was obtained, however deformities of the feet made the use of compression and shoes difficult. Thus the patient was submitted to surgery to remove deformities

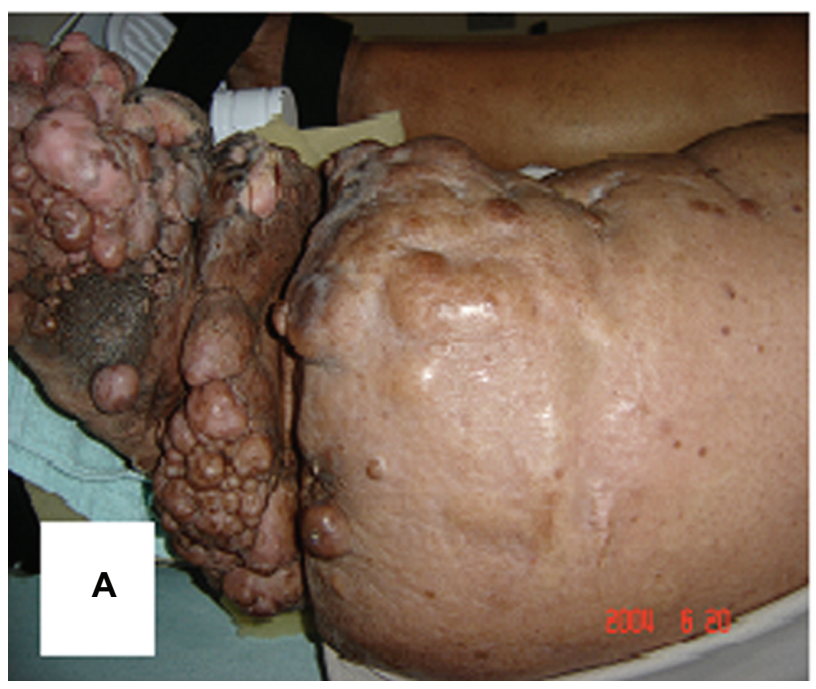

with 870 and 780 grams of tissue being resected from the feet. The shape of the feet was then adapted so that a compression mechanism could be used. After surgery, nonelastic bandaging was employed and maintained until scarring was complete (two months). The treatment of lymphedema continued with further reductions in size. In this case, intensive treatment of eight hours daily was maintained for 15 days using compression therapy, manual lymph drainage and mechanical lymph drainage utilizing the RAGodoy apparatus until the legs were within the normal size range. The patient was then able to perform day-to-day activities such as going for a walk, driving a car, washing and dressing, and working. Currently the patient attends the clinic for monthly followups for volumetric evaluations and the patient is counseled

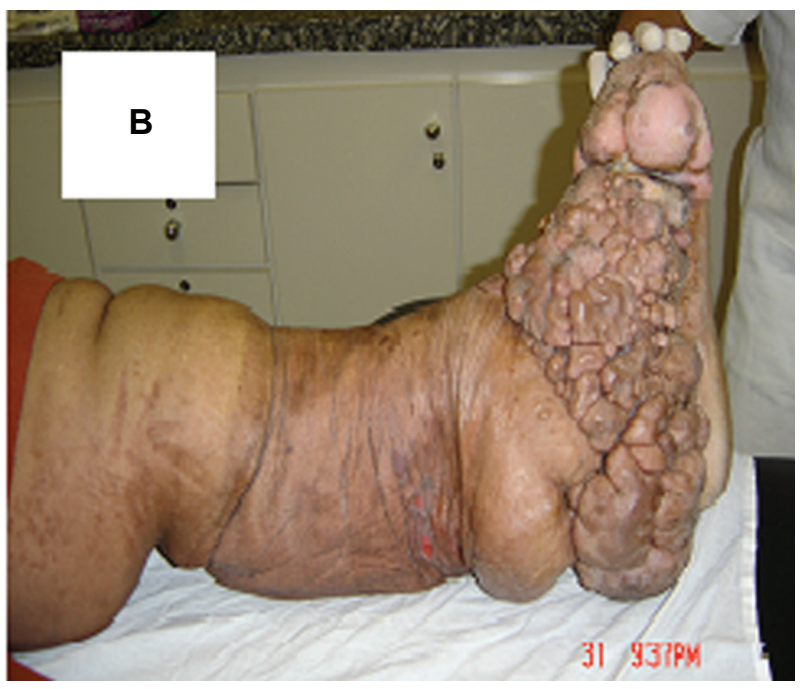

Figure 2 The leg at the start of treatment and during clinical treatment. 

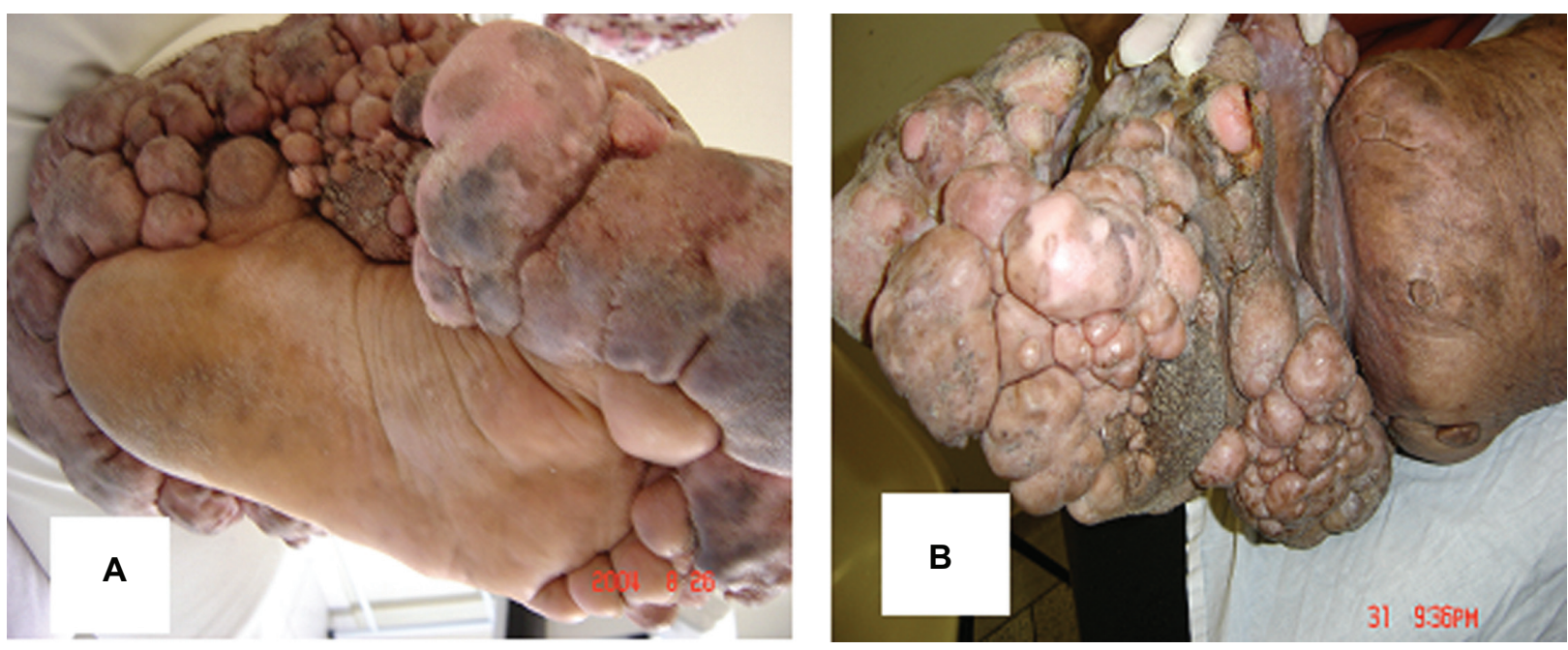

Figure 3 The foot on the day of the surgery.

about lymphedema; there is no cure for this disease, but the size of the limbs can be maintained within the normal range by following the treatment guidelines.

\section{Case report 2}

The case of a 56-year-old patient with congenital lymphedema that evolved to elephantiasis is reported (Figures 3 and 4). The patient was submitted to intensive clinical treatment of the lymphedema of six to eight hours per day. Treatment included manual and mechanical lymph drainage with compression therapy of the thigh and leg using a stocking made from a cotton-polyester material. After reduction in the size of the leg, the patient was submitted to surgery which removed 2970 grams of tissue from the foot. After surgery it was possible for the patient to utilize compression mechanisms on the feet. With further treatment of the lymphedema the size of the foot was reduced sufficiently for the patient to once again wear normal shoes.

\section{Discussion}

The current report shows the clinical experience of removing large lymphedematous deformities from the feet. The most important aspect of this approach was the maintenance of the integrity of the skin with resections being performed to remodel the feet in order for compression therapy to be possible. The initial clinical treatment allowed a reduction
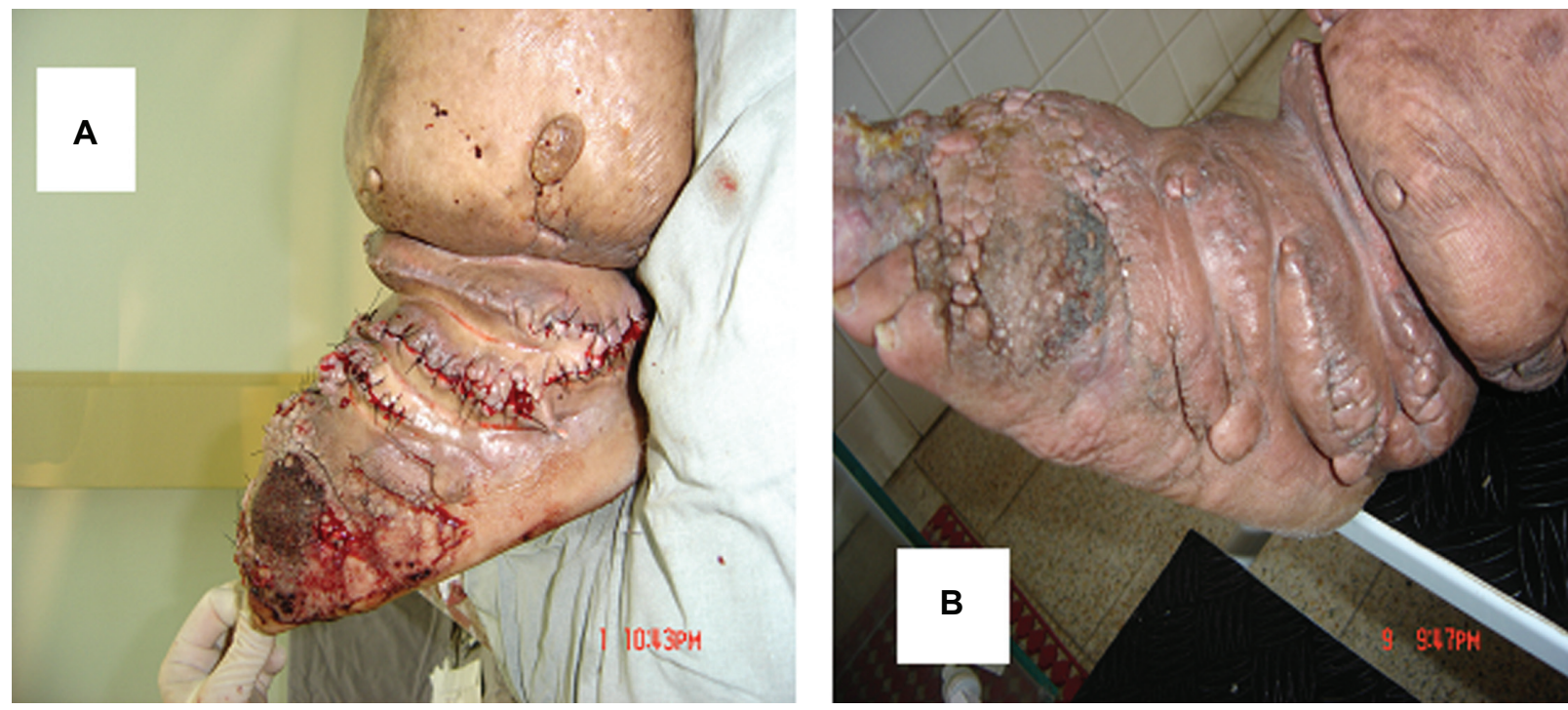

Figure 4 The immediate postoperative period after resection of 2970 grams of tissue and three monts after surgery. 
in fibrosis, reducing the size of the lesions and thus of the feet. From this stage it was possible to better identify the abnormal tissue masses and plan resections, as previously it had been impossible to clearly see the edges of tissue masses. The utilization of this approach would have been difficult without the initial clinical treatment producing reductions in size of the limbs. The planning of the surgery in these two cases was carefully discussed with experienced Brazilian plastic surgeons who recommended not performing the surgery before there was a reduction in size. This is important for the success of treatment as, attempts of resection without first reducing the size have not achieved comparable results.

The proposal is to remodel the foot so that compression can be adequately employed but without the surgical approach being too aggressive. Clinical treatment after surgery allowed these patients to obtain further reductions in the lymphedema of the feet and to start to wear normal shoes again. Thus this treatment improved the quality of life for the patients.

Intensive treatment of lymphedema immediately followed by surgery constitutes the most efficacious and fastest method of reducing the size of lymphedematous limbs. Additional to the intensive outpatient treatment of the lymphedema before the surgical procedure, these patients were hospitalized for two days prior to surgery for intensive treatment. This conduct reduces the swelling of the legs and feet as much as possible before surgery, thereby assisting the surgical technique.

\section{Disclosures}

The authors report no conflicts of interest in this work.

\section{References}

1. Foldi M, Foldi E, Kubik S. Lymphostatic disease. In: Textbook of Lymphology: For physicians and lymphedema therapists. Munich, Germany: Urban and Fischer; 2003:20.

2. Godoy JMP, Godoy MFG, Braile DM, Testoni B, Sanches RG. Dynamic evaluation of working pressures with gorgurão sleeves used in the treatment of lymphedema of the arm. Journal of Phlebology and Lymphology. 2008;1(1):5-7.

3. Kerketta AS, Babu BV, Rath K, Jangid PK, Nayak AN, Kar SK. A randomized clinical trial to compare the efficacy of three treatment regimens along with foot care in the morbidity management of filarial lymphoedema. Trop Med Int Health. 2005;10(7):698-705.

4. Godoy JMP, Godoy MFG. Manual lymph drainage: a new concept. J Vasc Br. 2004;3(1):77-80.

5. Johansson K, Tibe K, Weibull A, Newton RC. Low intensity resistance exercise for breast cancer patients with arm lymphedema with or without compression sleeve. Lymphology. 2005;38(4):167-180.

6. Godoy JMP, Silva HS. Prevalence of cellulitis and erysipelas in post-mastectomy patients after breast cancer. Arch Med Sci. 2007;3: 249-251.

7. Flour M. Creative compression treatment in challenging situations. Int J Low Extrem Wounds. 2008;7(2):68-74.

8. Godoy MFG, Godoy JMP, Braile DM. Pilot study with Myolymphokinetic activities in the treatment of lymphedema after breast cancer. Indian J Physiother Occup Ther. 2008;2(3):17-19.

9. de Godoy JM, Godoy M de F, Meza MC. Godoy and Godoy technique of cervical stimulation in the reduction of edema of the face after cancer treatment. QJM. 2008;101(4):325-326.

10. Kim DI, Huh SH, Hwang JH, Joh JH. Excisional surgery for chronic advanced lymphedema. Surg Today. 2004;34(2):134-137.

11. Godoy JMP, Godoy MFG. Development and evaluation of a new apparatus for lymph drainage: preliminary results. Lymphology. 2004;37(2):62-64.

12. Godoy JMP, Godoy MFG. Assessment of inelastic sleeves in patients with upper limb lymphoedema. Indian J Physiother Occup Ther. 2007;1(4):3-5.
International Journal of General Medicine

\section{Publish your work in this journal}

The International Journal of General Medicine is an international, peer-reviewed open-access journal that focuses on general and internal medicine, pathogenesis, epidemiology, diagnosis, monitoring and treatment protocols. The journal is characterized by the rapid reporting of reviews, original research and clinical studies across all disease areas.

\section{Dovepress}

A key focus is the elucidation of disease processes and management protocols resulting in improved outcomes for the patient.The manuscript management system is completely online and includes a very quick and fair peer-review system. Visit http://www.dovepress.com/ testimonials.php to read real quotes from published authors. 